\title{
New Year's resolution: one meeting-free week a quarter
}

\section{Protect time for deep thinking - it is crucial for productivity in a world of constant interaction, urges Heidi Rehm.}

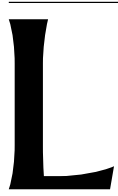

ast December, I analysed how much time I'd devoted to meetings and conference calls during the previous three months. Discounting the days when I had been travelling or at conferences and offsite meetings, I had averaged 8.5 hours a day. This year, I have a plan to protect work time:I'm scheduling one week a quarter during which meetings and conference calls are not allowed in my research group. So far, eight other groups have joined in this plan, and we expect others to come on board. More than 500 people expressed support for my call on Twitter.

I split my time between academic and clinical work, discovering the causes of rare disease, implementing genomics in health care, and building tools to support genomic medicine. I usually start work at 6 a.m., which allows me 2 hours of thoughtful work time: that includes following up on e-mails that demand special attention, and preparing for lectures and meetings, which typically begin at 8 a.m.I attend to Slack and e-mail communications in the evening. Writing and editing, preparing new presentations, and other more-substantive projects are for weekends and flights. That leaves little time for major projects, writing grants or doing deep critical or innovative thinking. This is what I want meeting-free weeks for.

I stumbled across the idea by accident. Several years ago, my holiday plans fell through, but I left the block on my calendar, preventing any meetings from being scheduled. When the week arrived, I confessed that I planned to spend the time at home with my children, who were on holiday from school. But with my younger son at basketball camp and my older daughter determined to be independent, I found myself free to dive into work with little disruption. I caught up on the long list of tasks that had piled up, particularly writing and editing. I got my e-mail inbox down to zero by the end of the week, and I also had time to watch films with my family in the evenings. It was magnificent!

I began doing this at least one week a year. Members of my lab quickly worked out what was going on, so I stopped pretending and made it clearer which weeks were actual holidays (when I really am mostly off the grid), and when it was 'Heidi's working at home without meetings' week. They respected my plan because they knew that I would get the things done that they needed from me.

Other groups at the Broad Institute in Cambridge, Massachusetts, including the Genomics Platform, the Data Sciences Platform and the lab of Daniel MacArthur, began implementing one meeting-free week per quarter.

\section{4 \\ Block out the weeks on the calendar immediately."}

Heidi Rehm is the chief genomics officer at Massachusetts General Hospital and the medical director at the Broad Institute's Clinical Research Sequencing Platform. e-mail: HREHM@ mgh.harvard.edu
It has been extremely positive, with people reporting being highly productive and able to dive into larger, sometimes daunting, projects that require longer stretches of dedicated attention. However, because more than three-quarters of my meetings and calls are outside the institute, those weeks still had at least 30 hours scheduled.

So, late last year, I extended the call to the broader genomics community. I crafted a proposal that avoids clashes with major genomics meetings and alternates which week of the month is free, to avoid repeated conflicts with monthly meetings (go.nature.com/2en531y). Several groups have since told me that they are working to implement the practice in their own programmes and labs.

My suggestion is to block out the weeks on the calendar immediately. Next, start cancelling and rescheduling meetings booked for those weeks. Standing weekly meetings can almost certainly be shed, as can many monthly ones, which will be disrupted only once a year. It is OK to keep very difficult-to-schedule meetings. Once the week arrives, ad hoc meetings are allowed, at the discretion of the group head, but these should have the specific purpose of accomplishing the work planned for the meeting-free week.

Although I have not found studies comparing approaches to curbing meetings, several surveys suggest that we are overly burdened with them. A survey of 182 senior managers across a range of industries found that about two-thirds felt that meetings cut into deep thinking and kept them from completing their own work (L. A. Perlow et al. Harvard Business Rev. 62-69; July-August 2017).

Of course, four weeks per year is a paltry amount of time for people whose job it is, essentially, to be innovative. Researchers, research groups and work places need to brainstorm their own systems to prevent meetings from degrading productivity, rigour and innovation. Some people carve out one day per week without meetings, others a period of time each day. Some companies arrange companywide protected time. I encourage every person and programme to find a system that works for them and stick to it.

In addition to taking time out from meetings, notice other barriers to productivity, perhaps e-mail or social media. Create periods of time that are free from these distractions or give them up entirely. Take a sabbatical if a change of environment is needed.

Personal strategies aside, with today's extensive, globe-spanning collaborations, it makes sense to develop an international, coordinated effort across programmes and institutions, and find four weeks a year to align meetingfree time globally.

I encourage everyone to enjoy these quarterly fasts. Let's report back to one another at the end of the year. Perhaps it will help to bring the research community together more deeply. 